\title{
Dünya Petrol, Kömür ve Doğal Gaz Fiyatları ile BİST Elektrik Endeksi Arasındaki Nedensellik İlişkisi ve Oynaklık Yayılımı*
}

(Araştırma Makalesi)

The Causality Relationship Between World Oil Price, Coal Price and Natural Gas Price and BIST Electricity Index, and Volatility Spillover

Doi: 10.29023/alanyaakademik.887155

\section{Tuncay GÜMÜŞ}

Bilim Uzmant., İ̧sletme,

tncgms@hotmail.com

Orcid No: 0000-0003-4085-9752.

\section{Çiğdem KURT CíHANGIR}

Doç. Dr., Hitit Üniversitesi, İktisadi ve İdari Bilimler Fakültesi, İşletme ckcihangir@hitit.edu.tr

Orcid No: 0000-0003-1761-1038.

Bu makaleye atıfta bulunmak için: Gümüs, T. \& Kurt Cihangir, Ç. (2022). "Dünya Petrol, Kömür ve Doğal Gaz Fiyatları ile BISST Elektrik Endeksi Arasındaki Nedensellik İlişkisi ve Oynaklık Yayılımı ”, Alanya Akademik Bakış, 6(1), Sayfa No. 1587-1603.

\section{ÖZET}

Anahtar kelimeler: BIST Elektrik Endeksi, Petrol Fiyatlarl,

Kömür Fiyatlarl, Doğal Gaz Fiyatları.

Makale Geliş Tarihi: 26.02.2021

Kabul Tarihi:

12.01.2022

Keywords:

BIST Electricity Index, Oil Price, Coal Price, Natural Gas Price
Bu çalışmanin amacl, dünya petrol, kömür ve doğal gaz fiyatlarındaki değişikliklerin düzeltilmemiş ve piyasa faiz oranına göre düzeltilmiş BIST elektrik endeksinin getirisine etkisinin 17 Mayls 2010-29 Mayıs 2020 dönemi için araştırılmasıdır. Değişkenler arasındaki nedensellik ilişkisi Granger Nedensellik testi ile, oynaklık yayllımı ise $\operatorname{GARCH}(1,1)$ ADC ve BEKK yöntemleri ile incelenmistir. Analiz bulgularına göre, BIST 100 endeksi getirisi ile dünya petrol ve kömür fiyatlarındaki değişikliklerin düzeltilmiş BIST elektrik endeksi getirisi üzerinde güçlü bir oynaklık yayllma etkisi vardır. Buna karşın, dünya doğal gaz fiyatlarındaki değişikliklerin BIST elektrik endeksi getirisi üzerinde gerek nedensellik gerekse oynaklık yayılımı açısından bir etki tespit edilmemiştir.

\section{ABSTRACT}

This study aims to investigate the effect of changes in world oil, coal and natural gas prices on the return of the unadjusted and market interest rate adjusted BIST electricity index for the period of 17th May, 2010 - 29th May, 2020. The causality relationship between the variables is examined with the Granger Causality test, and the volatility spillover is examined using the GARCH $(1,1) A D C$ and BEKK methods. According to the analysis findings,

\footnotetext{
*Bu çalışma, Hitit Üniversitesi Lisansüstü Eğitim Enstitüsü’nde, Tuncay Gümüş tarafindan hazırlanan “Dünya Enerji Emtia Fiyatları ile Borsa İstanbul Elektrik Endeksi Arasındaki İlişkinin Belirlenmesi”" başlıklı yüksek lisans tezinin geliştirilmiş ve genişletilmiş halidir.
} 
return of BIST 100 index and changes in world oil and coal prices have a strong volatility spillover effect on the adjusted BIST electricity index return. Conversely, no effect of the changes in world natural gas prices in terms of both causality and volatility spillover has been detected on the BIST electricity index return.

\section{GİRIŞ}

Nüfus artışı ve teknolojideki gelişmeler elektrik enerjisine ihtiyacı da giderek artırmaktadır. Uluslararası Enerji Ajansı'nın Dünya Enerji Görünümü 2018 Raporu’nda; 2040 yılına kadar nüfus ve gelir artışının enerji talebini \%25 civarında artıracağı, Asya ülkelerinin enerji tüketiminde diğer bölgeleri geçerek dünyada en ön sıralara yerleşeceği, fosil enerji kaynaklarının da önemini koruyacağı konuları öne çıkmaktadır (DEKTMK, 2018). 2018 yılında toplam enerji arzının \%31'i petrol, \%27'si kömür ve \%23'ü doğal gaz olmak üzere toplam \%81'i fosil yakıtlardan oluşmuştur (IEA, 2020).

Petrol, kömür, doğalgaz gibi fosil yakıtlarla elektrik üretimi göreli olarak ucuz ve kolaydır; ancak bu kaynakların en büyük dezavantajı küresel ısınmaya, hava ve çevre kirliliğine yol açmaları ve rezervlerinin kısıtlı olmasıdır (IIASA, 2020, 910). Bu dezavantajlarına rağmen dünya elektrik üretiminde kullanılan kaynakların dağılımı incelendiğinde fosil yakıtların toplamdaki payı 2001 yılında \%64,6; 2018 yılında ise \%64,1'dir (\%37,9 kömür, \%23,2 doğal gaz ve $\% 3$ petrol) (BP, 2019).

Türkiye'de elektrik üretimi kaynaklarına göre incelendiğinde, 2001 y1lında petrol \%8,5, kömür $\% 31,3$ ve doğal gaz \%40,3 pay alırken; 2019 yılında ilgili paylar sırasılyla $\% 0,23, \% 37,2$ ve \%18,6 olarak gerçekleşmiştir (TEİAŞ, 2020; BP, 2019). Buna göre, 2019 y1lında elektrik üretiminde doğal gazın ve petrolün payındaki dramatik düşüşe karşın; toplam elektrik üretiminin \%56'sı fosil yakıtlardan -petrol, kömür ve doğal gaz- elde edilmiştir. Türkiye'de kömürün \%60, doğal gazın \%99 ve petrolün \%94 oranında ithalat yolu ile karşılandığı (ETKB, 2020) dikkate alındığında, bu emtia fiyatlarındaki dalgalanmaların elektrik şirketlerinin getiri performanslarını etkilemesi beklenen bir durumdur. Enerji emtialarındaki fiyat artışları, bunları girdi olarak kullanan şirketlerin maliyetlerini artırarak kârlarının düşmesine neden olmaktadır (Oberndorfer, 2009; Schernikau, 2016). Aynı zamanda Türkiye'nin dünyadaki en yüksek petrol vergi oranlarına sahip ülkelerden biri olması nedeniyle (Ordu ve Soytaş, 2015:2150), elektrik endeksinin getirisinin petrol, kömür ve doğal gaz fiyatlarındaki değişimler açısından benzer ülkelerden ayrışması beklenmektedir. $\mathrm{Bu}$ durum, özellikle küresel yatırımcılar için çeşitlendirme firsatı olarak değerlendirilebilir.

Türkiye'de, dünya petrol, kömür ve doğal gaz fiyatlarındaki değişikler ile borsada işlem gören elektrik şirketlerinin getiri performanslarının göstergesi olan elektrik endeksi arasındaki ilişki bazı araştırmacılar tarafindan incelenmiştir. Örneğin, Güler vd. (2010), Soytaş ve Oran (2008), Eryiğit (2009); Soytaş ve Oran (2011); Abdioğlu ve Değirmenci (2014); Vardar vd. (2018) çalışmalarında petrol fiyat hareketleri ile BIST elektrik endeksi arasındaki ilişkiyi; Gürlevik ve Gazel (2020) petrol fiyatları, elektrik endeksi ve elektrik fiyatları arasındaki ilişkiyi; Ordu ve Soytaş (2016) ise petrol ve doğal gaz fiyatları ile BIST elektrik endeksi arasındaki ilişkiyi araştırmışlardır. Şimdiye kadar yapılan çalışmalarda, kömür fiyat hareketlerinin elektrik şirketlerinin performanslarına etkisinin araştırılmaması literatürdeki bir boşluk olarak değerlendirilmiştir. Zira elektrik üretiminde önemli bir oranda kömür kullanılmaktadır TEİAŞ, 
2020; BP, 2019). Bu anlamda, bu çalışmada 17 Mayıs 2010 - 29 Mayıs 2020 döneminde üç enerji emtiasının -petrol, kömür ve doğal gaz- fiyatlarındaki değişikliklerin BIST elektrik endeksinin getirisine etkisi hem nedensellik hem de oynaklık yayılması (simetrik - asimetrik) açısından araştırılmıştır. Çalışmanın katkıları şu şekilde sıralanabilir: Birincisi, elektrik üretiminde kullanılan petrol, kömür ve doğal gazın fiyatlarındaki değişimlerin BIST elektrik endeksine etkisinin eş zamanlı olarak araştırılmasıdır. Bu sayede, daha belirgin ve hedefe yönelik bir elektrik üretim politikasının belirlenmesine yardımcı olunabilir. İkincisi, Türkiye'de enerji ihtiyacının büyük bir kısmının ithalat yoluyla karşılandığı dikkate alındığında, bu çalışma ile döviz kurlarının (Dolar/TL) BIST elektrik endeksinin getirisi üzerindeki etkisinin incelenmesidir. Üçüncüsü, finansal piyasalar arasındaki oynaklık yayılması daha çok enerji emtiaları, özellikle petrol ile gösterge borsa endeks(ler)i için araştırılmıştır (Park ve Ratti, 2008; Narayan ve Narayan, 2010; Kapusuzoglu, 2011; Sadorsky, 2014; Arouri vd., 2011, 2012; Ewing ve Malik, 2016). Bu çalışmada ise petrol, kömür, doğal gaz fiyatları, BIST100 gösterge endeksi ve Dolar/TL kurundaki değişimler ile BIST elektrik endeksinin getirisindeki değişim arasındaki ilişki incelenerek sektörel bir bakış açısı belirlenmeye çalışılmıştır. Bu amaçla Soytaş ve Oran (2011) çalışması esas alınarak, ilgili değişkenlerin hem BIST elektrik sektör endeksinin getirisine hem de bu getirinin risksiz faiz oranından (gösterge tahvil faiz oranı) farkı alınarak hesaplanan düzeltilmiş BIST elektrik endeksi getirisine etkisi araştırılmıştır. Böylece, BIST elektrik sektör endeksini etkileyen genel faktörlerin yanı sıra sektöre özgü faktörler de belirlenmiştir. Dördüncüsü, özellikle uluslararası yatırımcılara enerji emtiaları ve enerji sektörü hisse senedi piyasası ile ilgili portföy oluştururken planlama yapabilecekleri bilgilerin sunulmasıdır. Son olarak, bu çalışma, kömür fiyatları ile BIST Elektrik endeksi arasındaki nedensellik ilişkisini ortaya koyan literatürdeki ilk çalışma olma özelliği taşımaktadır.

Çalışmanın planı şu şekildedir: İkinci bölümde literatür araştırması sunulmuştur. Üçüncü bölümde, değişkenler tanıtılarak temel analiz olarak Granger Nedensellik Testi uygulanmıştır. Dördüncü bölümde, değişkenler arasındaki getiri ve volatilite yayılmasına ilişkin ekonometrik uygulamanın ardından son kısımda, analiz sonuçları değerlendirilerek öneriler sunulmuştur.

\section{LITERATÜR}

Literatür araştırması sonucunda enerji emtialarının elektrik fiyatları ile veya elektrik endeksi ile ilişkisini araştıran çalışmalar olduğu belirlenmiştir. Elektrik fiyatları, elektrik üretim ve/veya dağıtım şirketlerinin karlılığını doğrudan etkileyen bir faktördür. Buna karşın elektrik sektör endeksi, enerji alanında faaliyet gösteren şirketlerin genel performanslarını yansıtmaktadır. Dolayısıyla, literatür incelemesi, enerji emtiaları ile elektrik fiyatları arasındaki ilişkiyi araştıran çalışmalar ve enerji emtiaları ile elektrik sektör endeksi arasındaki ilişkiyi araştıran çalışmalar olarak iki alt bölümde sunulmuştur.

Enerji emtiaları ile elektrik fiyatları arasındaki ilişkiyi araştıran çalışmalardan; döviz kuru ve petrol fiyatlarının elektrik fiyatlarını etkilediği bulgusuna ulaşan Nakajima ve Hamori (2012), Muñoz ve Dickey (2009), Moutinho vd. (2011) çalışmalarının bulgularına karşın, Mjelde ve Bessler (2009) elektrik fiyatlarının doğal gaz fiyatlarını ve doğal gaz fiyatlarının da petrol fiyatlarını etkilediğini belirtmiştir. Diğer taraftan, Mohammadi (2009), 1960 - 2007 dönem için ABD'de kömür, doğal gaz ve petrol fiyatları ile elektrik fiyatları arasındaki ilişkiyi yıllık veriler kullanarak incelemiştir ve kömür fiyatları ile elektrik fiyatları arasında karşılıklı bir nedensellik ilişkisi olduğunu belirtmiştir. Obendorfer (2009), 2002 - 2007 döneminde petrolün, doğal gazın ve kömürün fiyat hareketleri ve oynaklıkları ile Avrupa'da faaliyet gösteren 12 enerji üretim 
ve enerji dağıtım şirketinin hisse senedi getirileri arasındaki ilişkiyi GARCH yöntemi ile incelemiştir. Çalışmadan elde edilen bulgulara göre, petrol fiyat artışları, enerji dağıtım şirketlerinin hisse senetlerinin getirilerini olumsuz etkilerken; enerji üretim şirketlerinin hisse senetlerinin getirilerini ise olumlu yönde etkilemektedir. Enerji hisse senedi getirileri ile doğal gaz piyasası gelişmeleri arasında bir ilişki tespit edilmemiştir. Son olarak, kömür fiyatlarındaki bir artış, şirketlerin hisse senetlerinin getirilerini olumsuz etkilemektedir. Obendorfer (2009), Elektrik üretiminde petrole kıyasla çok daha geniş ölçekte kömür kullanılmasına rağmen, fiyat etkisi açısından kömürün petrole göre daha az etkili olduğunu belirtmiştir.

Enerji emtiaları ile elektrik fiyatları arasındaki ilişkiyi oynaklık yayılımı açısından araştıran çalışmalar da vardır. Örneğin, Green vd. (2018), Almanya enerji piyasasında doğal gaz, kömür fiyatlarındaki ve karbon emisyonlarındaki şokların elektrik fiyatlarına etkisini $2008-2016$ dönemi için araştırmışlardır. Buna göre, doğal gaz ve kömür fiyatlarındaki değişimin, elektrik fiyatları üzerinde ihmal edilemeyecek ölçüde yayılma etkisi yarattığı sonucuna ulaşmışlardır. Bunun aksine Liu vd. (2020) 2007 - 2019 döneminde kömür, doğal gaz ve petrol fiyatlarından Avrupa'daki elektrik piyasalarına getiri ve oynaklık yayılmasını araştırmışlardır ve bu üç fosil yakıttan en fazla doğal gazın oynaklık yayılma etkisine sahip olduğunu belirtmiş̧lerdir.

Enerji emtia fiyatlarının enerji/elektrik sektör endeksine etkisini küresel ölçekte araştıran Nandha ve Faff (2008) petrol fiyatlarındaki şokların 35 DataStream küresel sektör endeksinin getirisine etkisini Nisan 1983 - Eylül 2005 dönemi için araştırmışlardır. Buna göre, petrol fiyatlarındaki artışların sektör endekslerini eşit veya eş zamanlı etkilememekle birlikte; madencilik, petrol ve gaz sektörleri dışındaki tüm sektörler için hisse senedi getirilerini olumsuz etkilediğini saptamışlardır. Demiralay ve Gencer (2014) beş MSCI gelişmekte olan piyasa sektör endeksi ile petrol fiyatları arasındaki getiri ve oynaklık yayılımını asimetrik GARCH (VAR-AGARCH) modeli ile 6 Ocak 1995 -27 Aralık 2013 dönemindeki haftalık verileri kullanarak incelemişlerdir. Buna göre, petrol piyasasından enerji endekslerine doğru negatif ve tek yönlü bir şok yayılımı (aktarımı) olduğunu belirtmişlerdir. Acaravcı, Öztürk ve Kandır (2012) ise çalışmalarında doğal gaz fiyatları ile AB üyesi 15 ülkenin hisse senedi fiyatları arasındaki uzun dönemli ilişkiyi ve nedensellik ilişkisini 1990 - 2008 dönemi için araştırmışlardır. Doğal gaz fiyatları ile hisse senedi getirileri arasında sadece belirli ülkeler için uzun dönem ilişki tespit edilmesine karşın, nedensellik açısından ilişkinin dolaylı olduğunu tespit etmişlerdir. Buna göre, doğal gaz fiyatlarındaki artış öncelikle sanayi üretimindeki büyümeyi etkilemekte ve bu etki hisse senedi getirilerine yansımaktadır.

Türkiye için yapılan çalışmalarda Güler vd. (2010) petrol fiyatlarının hem elektrik endeksi hem de bireysel enerji hisse senetleri arasındaki ilişkiyi araştırırken; Soytaş ve Oran (2008), Abdioğlu ve Değirmenci (2014), Eryiğit (2009), Vardar, Kurt-Gümüş ve Delice (2018), Soytaş ve Oran (2011) elektrik endeksi ile, Gürlevik ve Gazel (2020) ise elektrik endeksi ve elektrik fiyatları ile ilişkisini araştırmışlardır.

Güler vd. (2010), 10 Temmuz 2000 - 10 Ağustos 2009 döneminde İMKB'de işlem gören enerji hisse fiyatları, elektrik endeksi ile petrol fiyat değişimleri arasındaki ilişkiyi regresyon modeliyle analiz etmişlerdir. Çalışma sonucunda, enerji hisseleri ile elektrik endeksi ve enerji fiyatlarının benzer davranış gösterdiğini ve hisse fiyatları ile elektrik endeksinin Brent petrol fiyatlarından etkilendiğini tespit etmişlerdir. Brent petrol fiyatındaki değişimin, İMKB elektrik endeksinin fiyat değişimlerinin Granger nedeni olduğunu saptamışlardır. 
Soytaş ve Oran (2008), 2 Mayıs 2003 - 1 Mart 2007 döneminde petrol fiyatlarındaki dalgalanmaların IMKB elektrik endeksine etkisini araştırdıkları çalışmalarında, petrol şoklarının döviz piyasası ve endeks kapsamındaki hisse senedi getirileri üzerinde anlamlı bir etkisinin olmadığını belirlemişlerdir. Benzer bir sonuca ulaşan çalışmada, Abdioğlu ve Değirmenci (2014) 2005 - 2013 dönemi günlük verilerini kullanarak petrol fiyatlarının sektör endekslerine etkisini araştırmışlardır. Buna göre, BIST elektrik endeksi ile petrol fiyatları arasında bir nedensellik ilişkisinin olmadığını belirtmişlerdir. Bu çalışmalara karşın, bazı araştırmacılar ise petrol fiyatları ile elektrik endeksi arasında anlamlı bir ilişki tespit etmişlerdir. Örneğin, Eryiğit (2009), sektör endeksleri petrol fiyatları arasındaki ilişkiyi 2000-2008 dönemi günlük frekansta veriler kullanarak OLS yöntemi ile incelemiş ve petrol fiyatlarındaki dalgalanmaların elektrik endeksinde önemli etkileri olduğunu saptamıştır. Vardar, Kurt-Gümüş ve Delice (2018) petrol fiyatlarındaki dalgalanma ile dört alt gruba ayırdıkları Borsa İstanbul sektör endeksleri arasındaki ilişkiyi, 1997 - 2016 dönemi günlük verileri üzerinden araştırmışlardır. Petrol fiyatlarının elektrik sektör endeksi ile uzun vadede eş bütünleşme ilişkisinin olmadığını; ancak petrol fiyatlarındaki değişikliklerin elektrik sektör endeksinin Granger nedeni olduğunu belirlemişlerdir. Bu sonuçlara göre, elektrik endeksi 1. çeyrekte petrol fiyat şoklarına olumlu yanıt verirken, 2. ve 3. çeyreklerde negatife dönmektedir. Soytaş ve Oran (2011) çalışmalarında 5.2.2003 - 3.1.2007 döneminde İMKB100 endeksi, elektrik endeksi ve petrol fiyatları arasındaki ilişkiyi Cheung - Ng (1996) ortalamada ve varyansta nedensellik analizi ile araştırmışlardır. Elektrik endeksi getirisini ve bu getiri ile pazar getirisi arasındaki fark olarak tanımladıkları düzeltilmiş elektrik endeksi getirisini ayrı ayrı modellemişlerdir. Analiz sonucunda, dünya petrol fiyatlarının elektrik endeksi ve düzeltilmiş elektrik endeksi getirisinin varyansta Granger nedeni olduğunu, ancak ana endeks getirisi için bir nedensellik olmadığını saptamışlardır. Gürlevik ve Gazel (2020) çalışmalarında 2010 Ç1 2019 Ç1 döneminde elektrik, doğal gaz ve petrol fiyatlarının BIST Elektrik endeksine etkisini, asimetrik ARDL (NARDL) yöntemini kullanarak araştırmışlardır. Analiz sonucunda BIST elektrik endeksi ile gaz fiyatları arasında uzun dönemde negatif yönlü ve anlamlı bir ilişki olduğu; ancak elektrik fiyatları ve petrol fiyatları arasında uzun dönemde anlamlı bir ilişki olmadığını belirlemişlerdir. Kısa dönem tahmin sonuçlarına göre araştırmacılar, elektrik endeksi ile petrol fiyatları arasındaki ilişkinin pozitif yönde olduğunu, bununla birlikte, gaz ile olan ilişkinin yönünün gecikmelere göre değiştiğini belirtmişlerdir.

Ordu ve Soytaş (2016), 2006 - 2013 döneminde petrol ve doğal gaz fiyatlarının borsa endeksi (BIST 100) ve BIST Elektrik endeksi getirilerine etkilerini araştırmışlardır. İnceledikleri dönemi, finansal kriz öncesi dönem (1 Ocak 2006 - 3 Temmuz 2008), finansal kriz dönemi (4 Temmuz 2008 - 24 Aralık 2008) ve finansal kriz sonrası dönem (25 Aralık 2008- 31 Aralık 2013) olarak üç alt döneme ayırmışlardır. Granger nedensellik testinin uygulandığ 1 analiz sonrasında petrol fiyatlarının hem BIST 100 hem de BIST Elektrik endekslerinin Granger nedeni olduğunu; doğal gaz fiyatlarının finansal kriz öncesi dönemde BIST Elektrik endeksinin Granger nedeni olmasına karşın; kriz döneminde ve kriz sonrası dönemde bu etkinin olmadığını saptamışlardır. İlarslan (2021) 1986-2019 döneminde uluslararası ham petrol, kömür ve doğal gaz fiyatlarının BIST 100 endeksine olan etkisini ARDL yöntemi ile incelemiştir. Değişkenler arasında eşbütünleşme ilişkisinin tespit edildiği çalışmanın diğer bulgularına göre BIST 100 endeksi ile petrol fiyatları arasında pozitif yönlü ve anlamlı, kömür fiyatları ile negatif yönlü ve anlamlı ve son olarak doğal gaz fiyatları ile negatif yönlü ve anlamsız ilişki vardır. 


\section{DEĞISSKENLERIN TANITILMASI VE TEMEL ANALIZ}

\subsection{Değişkenlerin Belirlenmesi}

$\mathrm{Bu}$ çalışmanın amacı, elektrik üretim kaynakları açısından büyük paya sahip olan enerji emtiaları; petrol, kömür ve doğal gaz fiyatlarındaki değişimler ile BIST100 endeks getirisinin BIST elektrik endeksinin getirisine etkilerinin belirlenmesidir. Çalışmada, Soytaş ve Oran (2011)'ı izleyerek, dünya petrol, kömür ve doğal gaz fiyatları olarak spot fiyatları kullanılmıştır. Türkiye'de enerji emtialarında dışa bağımlılık oranının yüksek olması nedeniyle, döviz kuru riskini temsil eden USD/TRY kuru modele dahil edilmiştir. Diğer taraftan, Chen vd. (1986) hisse senedi getirilerini açıklamada faiz oranlarının önemli olduğunu belirtmişlerdir. Bu nedenle Soytaş ve Oran (2011) çalışmasını izleyerek BIST elektrik endeksi getirisi ve bu getirinin risksiz faiz oranı olarak kabul edilen iki yıllık gösterge tahvilin getirisini aşan kısım olan, fazla (artık) getiri hesaplanmıştır. 17 Mayıs 2010 - 29 Mayıs 2020 dönemini günlük frekansta incelendiği çalışmada tüm değişkenlerin sürekli bileşik getirileri hesaplanmış ve kullanılan değişkenlere Tablo 1'de yer verilmiştir.

Tablo 1. Analizde Kullanılan Değişkenler ve Ölçüm Yöntemleri

\begin{tabular}{|c|c|c|}
\hline Değişkenler & Kaynak & Değişkenin Ölçüm Yöntemi \\
\hline Elektrik endeks getirisi (ELEN) & www.investing.com & $\begin{array}{l}\text { ELEN }=\left[\ln (\text { BIST Elektrik endeksi })_{t}-\right. \\
\left.\ln (\text { BIST Elektrik endeksi })_{t-1}\right]\end{array}$ \\
\hline $\begin{array}{l}\text { Düzeltilmiş Elektrik endeks } \\
\text { getirisi (DELEN) }\end{array}$ & www.investing.com & 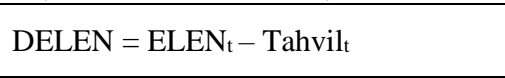 \\
\hline $\begin{array}{l}\text { Borsa İstanbul } 100 \text { endeks } \\
\text { getirisi (BIST100) }\end{array}$ & www.investing.com & $\begin{array}{l}\text { BIST100 }=\left[\ln (\text { BIST100 endeksi })_{t}-\right. \\
\left.\ln (\text { BIST100 endeksi })_{t-1}\right]\end{array}$ \\
\hline Doğal gaz (GAZ) & $\begin{array}{l}\text { ABD Enerji Bilgi } \\
\text { Yönetimi İdaresi }\end{array}$ & $\mathrm{GAZ}=\left[\ln (\mathrm{GAZ})_{\mathrm{t}}-\ln (\mathrm{GAZ})_{\mathrm{t}-1}\right]$ \\
\hline Kömür (KOM) & www.investing.com & $\mathrm{KOM}=\left[\ln (\mathrm{KOM})_{\mathrm{t}}-\ln (\mathrm{KOM})_{\mathrm{t}-1}\right]$ \\
\hline Petrol (PET) & $\begin{array}{l}\text { ABD Enerji Bilgi } \\
\text { Yönetimi İdaresi }\end{array}$ & $\mathrm{PET}=\left[\ln (\mathrm{PET})_{\mathrm{t}}-\ln (\mathrm{PET})_{\mathrm{t}-1}\right.$ \\
\hline Döviz kuru (KUR) & www.investing.com & $\mathrm{KUR}=\left[\ln (\mathrm{KUR})_{\mathrm{t}}-(\mathrm{KUR})_{\mathrm{t}-1}\right]$ \\
\hline
\end{tabular}

Not: Doğal gaz fiyatı olarak; Henry Hub doğal gaz spot fiyatı, petrol fiyatı olarak; WTI ham petrol spot fiyatları, kömür fiyatı olarak; New York Menkul Kıymetler borsasında işlem gören Dow Jones Coal (DJUSCL) spot fiyatları esas alınmıştır.

Çalışmada, bağımsız değişkenleri aynı olan iki ayrı model kurulmuştur. Birinci modelde bağımlı değişken olarak BIST Elektrik endeksinin getirisi (ELEN) alınmıştır. İkinci modelde kullanılan bağımlı değişken ise düzeltilmiş BIST Elektrik endeksi getirisidir (DELEN). Soytaş ve Oran (2011) çalışması esas alınarak DELEN, ELEN'in risksiz faiz oranı olarak kabul edilen iki yıllık gösterge tahvilin getirisini aşan kısım (artık getiri) olarak hesaplanmıştır. Yatırımcılar piyasa risk primindeki (artık getiri) değişimlere göre farklı tercihlerde bulunmakta ve bu durum varlık fiyatlarını etkilemektedir (Büberkökü, 2021). Bu sebeple çalışmada DELEN hesaplanarak piyasa risk primi değişimleri ile araştırmanın diğer bağımsız değişkenleri arasındaki ilişkinin ortaya çıkarılması amaçlanmıştır. Modellere ait fonksiyonlar aşağıdadır; 
$\mathrm{ELEN}=\mathrm{f}(\mathrm{BIST} 100, \mathrm{GAZ}, \mathrm{KOM}, \mathrm{PET}, \mathrm{KUR})$

DELEN $=\mathrm{f}(\mathrm{BIST} 100, \mathrm{GAZ}, \mathrm{KOM}$, PET, KUR $)$

Tablo 2. Değișkenlerin Tanımlayıcı İstatistikleri

\begin{tabular}{|l|c|c|c|c|c|c|c|}
\hline & ELEN & DELEN & BIST100 & GAZ & KOM & PET & KUR \\
\hline Ortalama & 0.0033 & 0.0000 & 0.0002 & -0.0004 & -0.0015 & 0.0000 & 0.0006 \\
\hline Ortanca & 0.0000 & 0.0006 & 0.0004 & 0.0000 & -0.0007 & 0.0003 & 0.0002 \\
\hline Maksimum & 8.5170 & 0.2182 & 0.0623 & 0.5253 & 0.3044 & 0.4258 & 0.1475 \\
\hline Minimum & -0.1230 & -0.2355 & -0.1106 & -0.4756 & -0.2833 & -0.2813 & -0.0799 \\
\hline Std. Sapma & 0.1695 & 0.0289 & 0.0141 & 0.0412 & 0.0369 & 0.0293 & 0.0090 \\
\hline Çarpıklık & 49.7045 & -0.7092 & -0.6718 & 0.5780 & -0.0901 & 1.4247 & 1.7921 \\
\hline Basıklık & 2496.183 & 11.9389 & 7.2652 & 35.2506 & 13.7496 & 49.0169 & 37.1914 \\
\hline Jarque-Bera & $6.61 \mathrm{E}+08$ & 8696.787 & 2123.063 & 110566.3 & 12271.62 & 225676.1 & 125478.5 \\
\hline Olasılık & $0.0000^{* * *}$ & $0.0000^{* * *}$ & $0.0000^{* * *}$ & $0.0000^{* * *}$ & $0.0000^{* * *}$ & $0.0000^{* * *}$ & $0.0000^{* * *}$ \\
\hline Toplam & 8.6502 & -0.0660 & 0.6437 & -1.0368 & -3.9959 & 0.0205 & 1.4775 \\
\hline $\begin{array}{l}\text { Std.Sapma } \\
\text { Kareleri Toplam1 }\end{array}$ & 73.2314 & 2.1275 & 0.5133 & 4.3274 & 3.4728 & 2.1923 & 0.2067 \\
\hline Gözlem say1s1 & 2548 & 2548 & 2548 & 2548 & 2548 & 2548 & 2548 \\
\hline *** simgesi \%1 düzeyinde istatistiksel anlaml11.̆g ifade etmektedir. \\
\hline
\end{tabular}

Değişkenlerin tanımlayıcı istatistiklerinin yer aldığı Tablo 2'ye göre, en yüksek oynaklığa (volatilite) sahip olan değişken ELEN, en düşük değişkenliğe sahip olan değişken ise KUR değişkenidir. Tüm değişkenlerin gözlem sayısı 2548 iken, bu değişkenlerden hiçbirinin JarqueBera istatistiğine göre $\% 1$ anlamlılık düzeyinde normal dağılıma sahip olmadığı gözlemlenmiştir. Ancak, doğası gereği, zaman serilerinin kuramsal (hipotetik) normal dağılıma sahip olması beklenmemelidir (Abdioğlu ve Değirmenci, 2014).

Değişkenlerin birim kök içerip içermedikleri Genişletilmiş Dickey-Fuller (ADF) ve PhilipsPerron (PP) birim kök testleri ile araştırılmıştır. Değişkenlerin düzey (I(0)) değerleri için sabitli modele göre uygulanan birim kök testlerinin değerleri Tablo 3'de sunulmuştur. Buna göre hem ADF hem de PP testinde tüm serilerin \%1 istatistiksel anlamlılık seviyesinde düzey değerlerinde durağan oldukları gözlenmektedir.

Tablo 3. Genişletilmiş Dickey-Fuller (ADF) ve Philips-Perron (PP) Birim Kök Testleri Tahmin Sonuçarı

\begin{tabular}{|l|l|l|l|l|}
\hline \multirow{2}{*}{ Değişkenler } & \multirow{2}{*}{$\begin{array}{l}\text { ADF Test İstatistiği } \\
(\text { Sabitli })\end{array}$} & Anlamlılık Düzeyi \\
\cline { 3 - 5 } & $-4.0890^{* * *}$ & $\% 1$ & $\% 5$ & $\% 10$ \\
\hline ELEN & $-25.649^{* * *}$ & -3.4326 & -2.8624 & -2.5672 \\
\hline DELEN & $-52.3809^{* * *}$ & -3.4326 & -2.8624 & -2.5672 \\
\hline BIST100 & -3.4326 & -2.8624 & -2.5672 \\
\hline GAZ & $-17.4207^{* * *}$ & -3.4326 & -2.8624 & -2.5672 \\
\hline KOM & $-25.4667^{* * *}$ & -3.4326 & -2.8624 & -2.5672 \\
\hline PET & $-14.1251^{* * *}$ & -3.4326 & -2.8624 & -2.5672 \\
\hline KUR & $-33.3622^{* * *}$ & -3.4326 & -2.8624 & -2.5672 \\
\hline & PP Test İstatistiği (Sabitli) & Anlaml1lk Düzeyi & \multicolumn{2}{l|}{} \\
\cline { 2 - 5 } & & $\% 1$ & $\% 5$ & $\% 10$ \\
\hline ELEN & -3.4326 & -2.8624 & -2.5672 \\
\hline
\end{tabular}




\begin{tabular}{|l|l|l|l|l|}
\hline DELEN & $-52.4309^{* * * *}$ & -3.4326 & -2.8624 & -2.5672 \\
\hline BIST100 & $-52.3716^{* * *}$ & -3.4326 & -2.8624 & -2.5672 \\
\hline GAZ & $-51.1738^{* * *}$ & -3.4326 & -2.8624 & -2.5672 \\
\hline KOM & $-49.6763^{* * *}$ & -3.4327 & -2.8624 & -2.5672 \\
\hline PET & $-55.2988^{* * *}$ & -3.4326 & -2.8624 & -2.5672 \\
\hline KUR & $-47.8690^{* * *}$ & -2.4326 & -2.8624 & -2.5672 \\
\hline Not: ${ }^{* * *},{ }^{* *},{ }^{*}$, sirasiyla \%1, \%5 ve \%10 istatistiksel anlamll11k seviyesini ifade etmektedir. \\
\hline
\end{tabular}

Birim kök araştırmasında, geleneksel birim kök testlerinin aksine, serilerdeki yapısal kırılma durumunu dikkate alan Zivot Andrews (1992) birim kök testi kullanılmıştır. Bu sayede, serilerin durağan olup/olmadığı kararı daha güvenilir bir biçimde test edilebilir. Zivot-Andrews (1992) birim kök testine göre serinin durağanlığı hakkında karar verilirken; seri için hesaplanan $\mathrm{t}$ istatistik değeri belirli istatistiksel anlamlılık seviyesindeki Zivot-Andrews kritik değerleri ile karşılaştırılır. Buna göre, $t$ istatistik değerinin mutlak ifadesi, kritik değerden büyükse serinin durağan olduğu (serinin birim kök içerdiği H0 hipotezi reddedilir); küçükse serinin durağan olmadığı (H0 hipotezi kabul edilir) kararı verilir (Yılancı, 2009: 328). Çalışmada kullanılan değişkenler için tahmin edilen yapısal kırılmayı dikkate alan Zivot-Andrews Test sonuçları Tablo 4'te verilmiştir. Buna göre, ilgili değişkenlerin yapısal kırılmayla birlikte durağanlıklarının sürdüğü belirlenmiştir.

Tablo 4. Zivot-Andrews Birim Kök Testi Tahmin Sonuçları

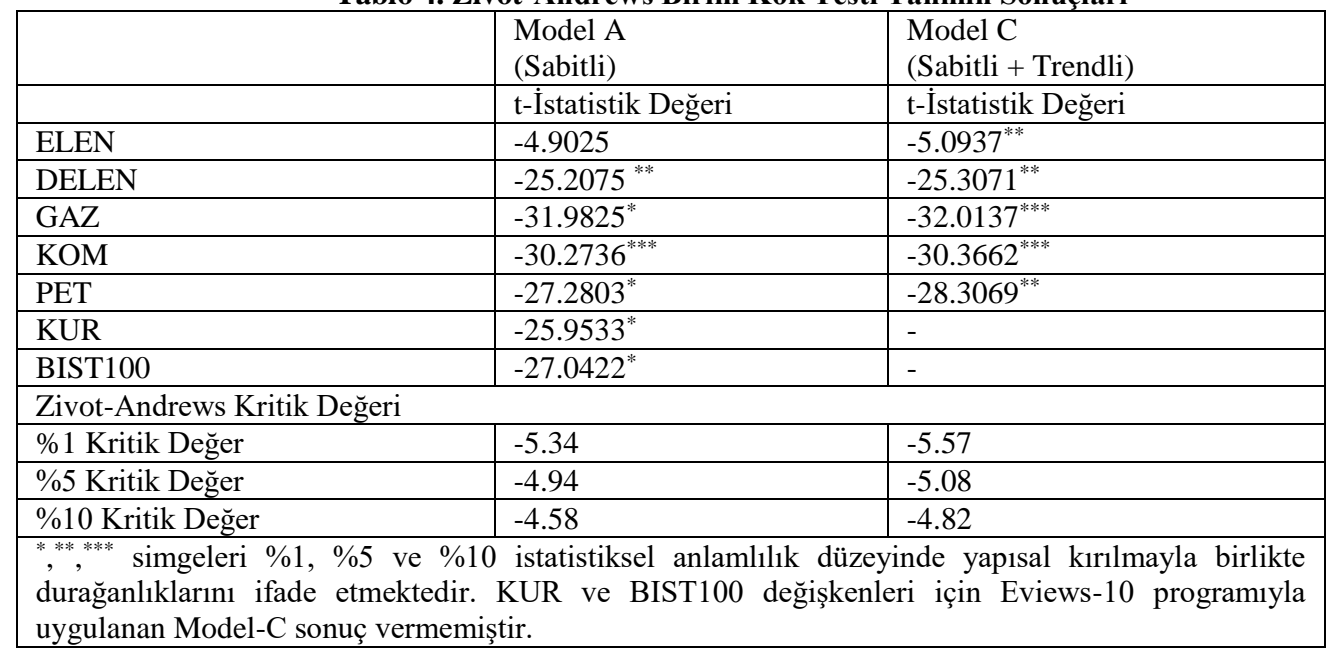

Her iki model için de gecikme uzunluğu Akaike Bilgi Kriterine göre belirlenmiştir (Bknz Ek1) Buna göre, gecikme uzunlukları ELEN için kurulan modelde 10, DELEN için kurulan modelde 8 olarak belirlenmiştir.

\subsection{Granger Nedensellik Testi Uygulaması}

Değişkenler arasında bir neden-sonuç ilişkisinin olup olmadığını tespit etmede kullanılan ve ilişki varsa bu ilişkinin yönünü belirleyen Granger nedensellik testi tahmin sonuçları Tablo 5 'te verilmiştir. 
Tablo 5. Granger Nedensellik Testi Tahmin Sonuçları

\begin{tabular}{|c|c|c|c|c|c|c|c|}
\hline \multicolumn{8}{|c|}{ Bağımsız Değişkenler } \\
\hline \multirow{7}{*}{ 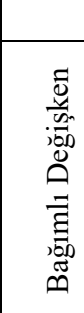 } & & ELEN & BIST100 & GAZ & KOM & PET & KUR \\
\hline & ELEN & - & 15.1519 & 9.57811 & $37.3727^{* * * *}$ & $37.5768^{* * * *}$ & 12.0930 \\
\hline & BIST100 & $2676.273^{* * *}$ & - & 9.7736 & $19.2255^{* *}$ & 15.6751 & 6.9766 \\
\hline & GAZ & 8.3562 & 4.5651 & - & 18.1330 & 9.8556 & 3.4464 \\
\hline & KOM & $55.1403^{* * *}$ & 12.1185 & 13.6030 & - & $46.7408^{* * *}$ & 7.0868 \\
\hline & PET & $32.8016^{* * * *}$ & 6.5897 & 10.7178 & $54.9334^{* * * *}$ & - & 10.6092 \\
\hline & KUR & $262.5985^{* * *}$ & 9.9875 & 5.7557 & 15.6472 & 12.3687 & - \\
\hline \multicolumn{8}{|c|}{ Tablo 5_B } \\
\hline & & \multicolumn{6}{|c|}{ Bağımsız Değişkenler } \\
\hline & & DELEN & BIST100 & GAZ & KOM & PET & KUR \\
\hline \multirow{6}{*}{ 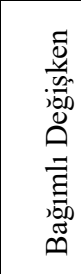 } & DELEN & - & $22.3688^{* * *}$ & 6.1462 & 10.5253 & 2.6382 & $135.7176^{* * *}$ \\
\hline & BIST100 & $17.8609^{* * *}$ & - & 6.3460 & $22.3608^{* * * *}$ & 11.6097 & $14.4147^{*}$ \\
\hline & GAZ & 4.6918 & 5.6024 & - & 16.5583 & 6.7140 & 3.2630 \\
\hline & KOM & 12.5223 & 10.9174 & 10.1962 & - & $41.2980^{* * * *}$ & 5.8816 \\
\hline & PET & 12.4993 & 8.9330 & 10.5318 & $55.2394^{* * *}$ & - & 8.9328 \\
\hline & KUR & 6.7591 & 7.3575 & 2.7268 & 12.0596 & 10.7738 & - \\
\hline
\end{tabular}

Tablo 5_A'da ELEN için uygulanan Granger nedensellik testi tahmin sonuçları verilmiştir. Buna göre; petrol ve kömür fiyatlarındaki değişim ve ELEN ile hem petrol hem de kömür fiyatlarındaki değişim arasında karşılıklı nedensellik ilişkisi olduğu tespit edilmiştir. Ayrıca, ELEN'den BIST100'e ve KUR'a doğru bir nedensellik ilişkisinin olduğu görülmektedir. Dikkate değer bir tahmin sonucu olarak, doğal gazın hiçbir değişkenle nedensellik ilişkisinin olmadığı belirlenmiştir. Tablo 5_B'de ise DELEN için uygulanan Granger nedensellik testi tahmin sonuçları verilmiştir. Buna göre, petrol ve kömür fiyatlarındaki değişim ve DELEN ile BIST 100 getirileri arasında karşılıklı nedensellik ilişkisi olduğu belirlenmiştir. Kömür fiyatlarındaki değişimin BIST 100 getirisindeki değişimin Granger nedeni olduğu ve döviz kurundaki değişimin de hem DELEN'in hem de BIST 100 getirisindeki değişsimin Granger nedeni olduğu tespit edilmiştir. Son olarak, bu modelde de doğal gazın hiçbir değişkenle nedensellik ilişkisinin olmadığı belirlenmiştir.

\subsection{Ampirik Model}

\subsubsection{Ampirik Model (Simetrik - Asimetrik Yayılma Modeli)}

Çalışmanın bu bölümünde, dünya petrol, kömür, doğal gaz fiyatlarındaki değişim ile BIST 100 endeksi getirisi ve döviz kurunun, düzeltilmemiş ve düzeltilmiş BIST elektrik endeksi getirisinde neden olduğu getiri ve oynaklık yayılma etkileri $\mathrm{Ng}$ (2000) metodolojisi esas alınarak araştırılmıştır. Oynaklık dalgalanmalarının büyüklügünü ve yapısını ölçmek için iki değişkenli GARCH $(1,1)$ ve tek değişkenli oynaklık yayılma modeli ADC (Asymmetric Dynamic Covariance) ve BEKK yöntemleri uygulanmıştır. Buna göre, ilk olarak asimetrik etkileri olan ve olmayan genel ADC modeli tahmin edilir. Sonrasında, BEKK modeli, asimetri ile veya asimetri olmadan, ADC modelinin özel bir durumu olarak kabul edilir. 
İki ayrı modelin tahmin edildiği çalı̧̧mada değişkenler $R_{\text {ELEN }_{i}}$ ve $R_{\text {DELEN }_{i}} i=$ BIST100, GAZ, KOM, KUR, PET şeklindedir ve ilk aşamadaki model, GARCH $(1,1)$ aşağıda verilmiştir:

$$
\begin{aligned}
& R_{E L E N_{i, t}}=\alpha_{E L E N_{i}}+e_{E L E N_{i, t}}, \quad e_{E L E N_{i, t}}=\sqrt{\sigma_{E L E N_{i, t}}^{2}} Z_{E L E N_{i, t}} \\
& \sigma_{E L E N_{i, t}}^{2}=w_{E L E N_{i}}+\beta_{E L E N_{i}} R_{E L E N_{i, t-1}}^{2}+\gamma_{E L E N_{i}} \sigma_{E L E N_{i, t-1}}^{2}
\end{aligned}
$$

Burada (1) ve (2) eşitlikleri sırasıyla getiri ve oynaklık eşitliğini ifade etmektedir. $Z_{E L E N_{i, t}}, 0$ ortalama 1 varyans değeri ile birbirinden bağımsız ve aynı dağılıma sahiptir. Ayrıca $w_{E L E N_{i}}, \beta_{E L E N_{i}}$ ve $\gamma_{E L E N_{i}}>0$ ve $\beta_{E L E N_{i}}+\gamma_{E L E N_{i}}<1$ şeklinde kısitlamaları vardır. Buna göre, her $i$ için (1) nolu eşitlikten elde edilen $e_{E L E N N_{i, t}}$ değerleri, bağımsız değişkenlerin bağımlı değişken olan ELEN ve DELEN üzerindeki yayılma etkilerini araştırmak için kurulan GARCH $(1,1)$ modeline eklenir ve aşağıdaki gibi tanımlanır:

$$
\begin{aligned}
& R_{E L E N, t}=c_{0}+c_{1} R_{E L E N, t-1}+\sum_{i=B I S T 100}^{P E T} \gamma_{i} R_{E L E N i, t-1}+\sum_{i=B I S T 100}^{P E T} \delta_{i} e_{E L E N}+\varepsilon_{i, t}+\varepsilon_{E L E N, t} \\
& \sigma_{E L E N_{t}}^{2}=w_{E L E N}+\beta_{E L E N} R_{E L E N N_{t-1}}^{2}+\gamma_{E L E N} \sigma_{E L E N_{t-1}}^{2}
\end{aligned}
$$

Burada $w_{E L E N}, \beta_{E L E N}$ ve $\gamma_{E L E N}>0$ ve $\beta_{E L E N}+\gamma_{E L E N}<1$. Buna göre, $\gamma_{i}$ ve $\delta_{i}$ katsayılar1 sırasıyla getiri ve oynaklık yayılma etkilerini göstermektedir. Benzer model DELEN için de kurulmuştur. Getiri ve oynaklık yayılma etkilerinin istatistiksel olarak anlamlı olup olmadığııı kontrol etmek için Wald testi kullanılmıştır.

Kötü (olumsuz) haberlerin bağımlı değişken üzerindeki oynaklık yayılmasını iyi (olumlu) haberlerden daha fazla etkilemesi olarak ifade edilen asimetrik yayılma etkisini araştırmak için (5) nolu eşitlik tanımlanmıştır (Bae ve Karolyi, 1994; De Santis ve Gerard, 1997; Ng, 2000):

$$
\begin{aligned}
& R_{E L E N, t}=c_{0}+c_{1} R_{E L E N, t-1}+\sum_{i=B \mathrm{IST100}}^{P E T} \gamma_{1 i} R_{E L E N, t-1}^{+}+\sum_{i=B I S T 100}^{P E T} \gamma_{2 i} R_{E L E N_{i, t-1}}^{-}+ \\
& \sum_{i=B I S T 100}^{P T} \delta_{1 i} e_{E L E N}^{+}+\sum_{i=B I S T 100}^{P E T} \delta_{2 i} e_{E L E N_{i, t}}^{-}
\end{aligned}
$$

Burada $R_{E L E N_{i}}^{+}, R_{E L E N_{i}}^{-}$artış ve azalış bilgisi içermektedir. Ayrıca, $e_{E L E N_{i, t}}^{+} e_{E L E N_{i, t}}^{-}$ise analizde kullanılan bağımsız değişkenlerin pozitif ve negatif şoklarını içermektedir. Asimetrik yayılma etkilerinin istatistiksel olarak anlamlılı̆̆ , yukarıdaki gibi, Wald testi ile araştırılmıştır. Buna göre, BIST100'den ELEN'e asimetrik getiri ve oynaklık yayılma etkileri sirasiyla $H_{0}: \gamma_{3}=\gamma_{4}$ ve $H_{0}: \delta_{13}=\delta_{14}$ hipotezleri ile test edilmiş̧ir. Boş hipotezin reddi durumunda asimetrik yayılma etkisinin olduğu kararı verilmiştir.

Tablo 6_A'da ELEN ve DELEN için getiri yayılma etkilerine ait tahmin sonuçları verilmiştir. Buna göre, hiçbir bağımsız değişkenden ELEN'e getiri yayılma etkisi yoktur. KUR'dan \%1 anlamlılık seviyesinde; PET, KOM ve BIST100 değişkenlerinden ise $\% 10$ anlamlılık seviyesinde DELEN'e getiri yayılma etkisinin olduğu belirlenmiştir. Bu durum, KUR ile DELEN arasındaki getiri geçişkenliğinin nispeten, güçlü olduğu anlamına gelmektedir. Tablo 6_B'de ise oynaklık yayılma etkisine ait tahmin sonuçları yer almaktadır. Buna göre, GAZ ve PET fiyatlarındaki oynaklığın ELEN üzerinde oynaklık yayılma etkisinin olduğu ve neredeyse aynı büyüklükteki bu etkinin farklı yönlerde gerçekleştiği saptanmıştır. GAZ'ın oynaklığındaki artış, bir şok, ELEN üzerinde negatif etki oluştururken; PET'deki bir şok ELEN'i pozitif yönde etkilemektedir. Diğer taraftan; BIST100, KOM, KUR ve PET değişkenlerindeki bir şok 
DELEN'i etkilemektedir. Burada en büyük oynaklık yayılma etkisinin BIST100'den kaynaklandığı görülmektedir.

Tablo 6. Getiri Yayılma Etkisi

Tablo 6_A: Getiri Yayılması

\begin{tabular}{|l|c|c|c|c|c|}
\hline \multirow{2}{*}{ ELEN } & BIST100 & GAZ & KOM & KUR & PET \\
\hline \multirow{2}{*}{ DELEN } & 0.24360 & -0.00577 & -0.02876 & 0.61610 & 0.07420 \\
\cline { 2 - 6 } & $(0.7323)$ & $(0.9724)$ & $(0.9138)$ & $(0.4257)$ & $(0.6145)$ \\
\hline & 0.05676 & -0.00154 & -0.01681 & -0.44929 & -0.02268 \\
\cline { 2 - 6 } & $\left(0.0842^{*}\right)$ & $(0.8519)$ & $\left(0.0727^{*}\right)$ & $\left(0.000^{* * * *}\right)$ & $\left(0.0648^{*}\right)$ \\
\hline
\end{tabular}

Tablo 6_B: Oynaklık Yayılması

\begin{tabular}{|l|l|l|l|l|l|}
\hline \multirow{3}{*}{ ELEN } & \multicolumn{1}{|c|}{ BIST100 } & \multicolumn{1}{|c|}{ GAZ } & \multicolumn{1}{c|}{ KOM } & \multicolumn{1}{c|}{ KUR } & \multicolumn{1}{c|}{ PET } \\
\hline \multirow{2}{*}{ DELEN } & -0.25477 & -0.24018 & 0.00362 & 0.36269 & 0.22944 \\
\cline { 2 - 6 } & $(0.7883)$ & $\left(0.0000^{* * *}\right)$ & $(0.9900)$ & $(0.4144)$ & $\left(0.0608^{*}\right)$ \\
\hline \multirow{2}{*}{$N$} & 1.08964 & -0.00156 & 0.02476 & -0.43624 & -0.02792 \\
\cline { 2 - 6 } & $\left(0.0000^{* * * *}\right)$ & $(0.8425)$ & $\left(0.0101^{* * *}\right)$ & $\left(0.0000^{* * *}\right)$ & $\left(0.0160^{* *}\right)$ \\
\hline
\end{tabular}

Not: p-değerleri parantez içinde verilmiştir. ${ }^{* * *},{ }^{* *},{ }^{*}$, sırasılyla $\% 1, \% 5$ ve $\% 10$ istatistiksel anlamlılık seviyesini ifade etmektedir.

Tablo 7'de wald test tahmin sonuçlarına ilişkin F-istatistik değerleri ve olasılık düzeyleri verilmiştir. Burada, bağımsız değişkenden bağımlı değişkene ortalama ve oynaklık yayılma etkisi yoktur şeklindeki H0 hipotezi test edilmiştir. Buna göre, GAZ, KUR ve PET'den ELEN'e; BIST100, KOM, KUR ve PET'den ise DELEN'e yayılma etkisinin olduğu belirlenmiştir.

Tablo 7. Wald Test Tahmin Sonuçları (Simetrik Yayılma Etkisi)

\begin{tabular}{|c|c|c|c|c|c|}
\hline & BIST100 & GAZ & KOM & KUR & PET \\
\hline \multirow{2}{*}{ ELEN } & \begin{tabular}{|l|}
0.12293 \\
\end{tabular} & 3.28363 & 0.00663 & \begin{tabular}{|l|}
4.68268 \\
\end{tabular} & \begin{tabular}{|l|}
4.15825 \\
\end{tabular} \\
\hline & $(0.8843)$ & $\left(0.0377^{* *}\right)$ & $(0.9934)$ & $\left(0.0093^{* * *}\right)$ & $\left(0.0157^{* *}\right)$ \\
\hline \multirow{2}{*}{ DELEN } & 1459.400 & 0.04149 & 5.63061 & 326.5584 & 4.13259 \\
\hline & $\left(0.0000^{* * * *}\right)$ & $(0.9594)$ & $\left(0.0036^{* * *}\right)$ & $\left(0.0000^{* * *}\right)$ & $\left(0.0161^{* *}\right)$ \\
\hline
\end{tabular}

Asimetrik yayılma etkisi, negatif bir şokun oynaklık üzerinde pozitif bir şoktan daha büyük bir etkiye neden olmasıdır. Tablo 8'de değişkenler arasındaki asimetrik yayılma etkisine ilişkin tahmin sonuçları verilmiştir. Tablo 8 incelendiğinde, hiçbir bağımsız değişkenden ELEN'e asimetrik yayılma etkisi yokken; bazı değişkenlerden DELEN'e asimetrik yayılma etkisinin olduğu görülmektedir. Buna göre, KOM'daki olumsuz bir haber DELEN getirisini artırıcı yönde; PET'deki olumsuz bir haber ise DELEN getirisini azaltıcı yönde bir asimetrik yayılma etkisine yol açmaktadır. Diğer taraftan, GAZ'daki pozitif bir şok DELEN getirindeki oynaklığı azaltıcı; KUR'daki pozitif bir şok ise DELEN getirisindeki oynaklığı artırıcı yönde bir yayılma etkisi yaratmaktadır.

Tablo 8. Asimetrik Yayılma Etkisi

\begin{tabular}{|l|l|l|l|l|l|l|}
\hline & & BIST100 & \multicolumn{1}{|c|}{ GAZ } & \multicolumn{1}{c|}{ KOM } & \multicolumn{1}{c|}{ KUR } & \multicolumn{1}{c|}{ PET } \\
\hline \multirow{4}{*}{ ELEN } & $\gamma_{1 i}$ & -0.05081 & 0.00886 & -0.01013 & -0.03340 & -0.005955 \\
\cline { 2 - 7 } & & $(0.2495)$ & $(0.5256)$ & $(0.5114)$ & $(0.6364)$ & $(0.6766)$ \\
\cline { 2 - 7 } & $\gamma_{2 i}$ & -0.01440 & 0.00309 & -0.01297 & 0.09448 & -0.00217 \\
\cline { 2 - 7 } & & $(0.6836)$ & $(0.7788)$ & $(0.3467)$ & $(0.1691)$ & $(0.9219)$ \\
\hline
\end{tabular}


GÜMÜŞ \& KURT CIHHANGİR

\begin{tabular}{|l|l|l|l|l|l|l|}
\hline \multirow{5}{*}{} & $\delta_{1 i}$ & -0.02162 & 0.00056 & 0.01282 & -0.04113 & -0.00298 \\
\cline { 2 - 6 } & & $(0.6049)$ & $(0.9678)$ & $(0.4340)$ & $(0.5477)$ & $(0.8610)$ \\
\cline { 2 - 6 } & $\delta_{2 i}$ & -0.01629 & 0.00724 & 0.02082 & -0.00896 & -0.01892 \\
\cline { 2 - 6 } & & $(0.6750)$ & $(0.5649)$ & $(0.1197)$ & $(0.9090)$ & $(0.3159)$ \\
\cline { 2 - 7 } & $\gamma_{1 i}$ & -0.00205 & 0.00175 & 0.00387 & -0.11324 & -0.00391 \\
\cline { 2 - 7 } & & $(0.9714)$ & $(0.9277)$ & $(0.8667)$ & $(0.3020)$ & $(0.8910)$ \\
\cline { 2 - 7 } & $\gamma_{2 i}$ & -0.04949 & -0.00231 & 0.05688 & 0.04466 & -0.07536 \\
\cline { 2 - 7 } & & $(0.4255)$ & $(0.9098)$ & $\left(0.0046^{* * *}\right)$ & $(0.6815)$ & $\left(0.0195^{* *}\right)$ \\
\cline { 2 - 7 } & $\delta_{1 i}$ & -0.05055 & -0.05441 & -0.01062 & 0.13379 & -0.01593 \\
\cline { 2 - 7 } & & $(0.4539)$ & $\left(0.0101^{* * *}\right)$ & $(0.6345)$ & $\left(0.0222^{* *}\right)$ & $(0.5937)$ \\
\cline { 2 - 7 } & $\delta_{2 i}$ & 0.07901 & 0.01972 & -0.00016 & 0.13764 & -0.01455 \\
\hline & $(0.1377)$ & $(0.2735)$ & $(0.9942)$ & $(0.2350)$ & $(0.6798)$ \\
\hline
\end{tabular}

Not: p-değerleri parantez içinde verilmiştir. ${ }^{* * *},{ }^{* *},{ }^{*}$, sırasıyla $\% 1, \% 5$ ve $\% 10$ istatistiksel anlamlılık seviyesini ifade etmektedir.

Kömür ve petrol fiyatlarındaki kötü haberler düzeltilmiş BIST elektrik endeksinin getirisinde asimetrik etkiye neden olmaktadır. Diğer taraftan, kur ve doğal gaz fiyatlarındaki pozitif şoklar, BIST elektrik endeksinin riskinde asimetrik etkiye neden olmaktadır.

Her bir bağımsız değişkenden ELEN'e veya DELEN'e getiri ve/veya oynaklık asimetrik yayılma etkisinin test edildiği Wald Testi tahmin sonuçları Tablo 9'da verilmiştir. ELEN için yapılan testte asimetrik yayılma etkisinin olmadığ PET değişkenlerinden DELEN'e getiri açısından asimetrik yayılma etkisinin olduğu; GAZ ve KUR değişkenlerinden ise oynaklık açısından asimetrik yayılma etkisinin olduğu tespit edilmiştir.

Tablo 9. Asimetrik - Wald Test Tahmin Sonuçları (Asimetrik Yayılma Etkisi)

\begin{tabular}{|c|c|c|c|c|c|c|}
\hline & & BIST100 & GAZ & KOM & KUR & PET \\
\hline \multirow{4}{*}{ ELEN } & Ortalama & 1.0296 & 0.3059 & 0.9742 & 0.9470 & 0.1104 \\
\hline & Olasıl1k & $(0.3573)$ & $(0.7364)$ & $(0.3776)$ & $(0.3880)$ & $(0.8955)$ \\
\hline & Volatilite & 0.3155 & 0.1883 & 2.1591 & 0.2338 & 0.5919 \\
\hline & Olasılık & $(0.7295)$ & $(0.8284)$ & $(0.1157)$ & $(0.7915)$ & $(0.5533)$ \\
\hline \multirow{4}{*}{ DELEN } & Ortalama & 0.3478 & 0.0082 & 4.8174 & 0.5371 & 3.0455 \\
\hline & \begin{tabular}{|l|} 
Olasılık \\
\end{tabular} & $(0.7062)$ & $(0.9918)$ & $\left(0.0082^{* * *}\right)$ & $(0.5845)$ & $\left(0.0478^{* *}\right)$ \\
\hline & Volatilite & 1.1517 & 3.3536 & 0.1247 & 4.1648 & 0.3305 \\
\hline & Olasılık & $(0.3163)$ & $\left(0.0351^{* *}\right)$ & $(0.8828)$ & $\left(0.0156^{* *}\right)$ & $(0.7186)$ \\
\hline
\end{tabular}

\section{SONUÇ VE DEĞERLEDİRME}

Bu çalışmada, dünya petrol, kömür ve doğal gaz fiyatlarındaki değişimlerin ve BIST 100 endeksi getirisinin düzeltilmemiş ve piyasa faiz oranına göre düzeltilmiş BIST Elektrik endeksinin getirisine etkisi nedensellik ve oynaklık yayılımı açısından 17 Mayıs 2010 - 29 Mayıs 2020 dönemi için araştırılmıştır. Çalışmanın temel analiz bölümünde değişkenler arasındaki nedensellik ilişkisi Granger nedensellik testi ile incelenmiştir. Tahmin sonuçlarına göre; petrol fiyatları ile düzeltilmemiş BIST elektrik endeksinin getirisi (ELEN) arasında, Güler vd. (2010) çalışması ile uyumlu olarak, karşılıklı bir nedensellik ilişkisi tespit edilmesine karşın; düzeltilmiş BIST elektrik endeksinin getirisi (DELEN) arasında, Ordu ve Soytaş (2016) 
ile Mohanty vd. (2010) çalışmaları ile uyumlu olarak, bir nedensellik ilişkisinin olmadığı belirlenmiştir. Doğal gaz fiyatlarındaki değişim ile gerek düzeltilmemiş BIST elektrik endeksi (ELEN) gerekse düzeltilmiş BIST elektrik endeksi getirileri (DELEN) arasında bir nedensellik ilişkisinin olmadığı belirlenmiştir. Bu sonuç, Ordu ve Soytaş (2016)'ın çalışmalarında 2008 küresel kriz esnası ve kriz sonrası dönem için ulaştıkları bulgular ile uyumludur. Kömür fiyatları ile düzeltilmemiş BIST elektrik endeksi (ELEN) ve petrol fiyatları arasındaki ilişkinin karşılıklı olduğu; BIST100 endeksi arasında ise tek yönlü (kömürden borsa endeksine doğru) bir Granger nedensellik ilişkisi olduğu tespit edilmiştir. Borsa gösterge endeksi açısından, kurulan iki modelde de etkisi araştırılan enerji emtialarından sadece kömür fiyatlarındaki değişim BIST 100 endeksi getirisinin Granger nedenidir. Petrolde \%94, doğal gazda \%99 ve kömürde \%60 dışa bağımlılığın söz konusu olduğu Türkiye ekonomisinde doğal gaz ve petrol fiyatları ile BIST 100 endeksi getirisi arasında nedensellik ilişkisi olmaması durumunun, küresel piyasa ile olan entegrasyonda zayıflık olarak değerlendirmek mümkündür.

Analiz bulguları oynaklık yayılması açısından değerlendirildiğinde; düzeltilmemiş BIST elektrik endeksi getirisine (ELEN) incelenen değişkenlerden bir getiri yayılma etkisinin olmadığı; ancak, döviz kurundan düzeltilmiş BIST elektrik endeksinin getirisine (DELEN) doğru getiri yayılma etkisinin olduğu tespit edilmiştir. Getiri yayılması açısından BIST100 endeksi getirisi, dünya kömür ve petrol fiyatlarındaki değişimler ile düzeltilmiş BIST elektrik endeksinin getirisi (DELEN) arasındaki ilişki zayıf olsa da oynaklık (risk) yayılması açısından güçlü bir etkinin olduğu belirlenmiştir. Elde edilen bulgulara göre, şaşırtıcı biçimde, düzeltilmiş BIST elektrik endeksi getirisindeki (DELEN) en büyük oynaklığın kaynağı BIST 100 endeksinin getirisindeki değişimdir. Ayrıca, değişkenler arasındaki oynaklık yayılması kaynaklarının getiri yayılmasına göre daha fazla olduğu tespit edilmiştir. Döviz kurunun hem getirisindeki hem de oynaklığındaki bir artış düzeltilmiş BIST elektrik endeksinin getirisinde (DELEN) aynı yönde ve neredeyse aynı büyüklükte bir etkiye neden olmaktadır. Dünya kömür ve petrol fiyatlarındaki kötü haberler düzeltilmiş BIST elektrik endeksinin getirisinde (DELEN) asimetrik etkiye neden olmaktadır. Diğer taraftan, döviz kuru ve dünya doğal gaz fiyatlarındaki pozitif şoklar, düzeltilmiş BIST elektrik endeksi getirisinin (DELEN) oynaklığında asimetrik etkiye neden olmaktadır. Diğer bir ifadeyle, düzeltilmiş BIST elektrik endeksi getirisindeki (DELEN) asimetrik oynaklık yayılmasının, pozitif şoklara, negatif şoklardan daha duyarlı olduğunu söylenebilir.

Elde edilen bu bulgular, yatırımcıların, politika yapıcıların ve yöneticilerin karar alma süreçlerinde faydalı olacaktır. Dünya petrol ve kömür fiyatlarındaki ve kurdaki değişikliklerin düzeltilmiş BIST elektrik endeksi getirisi üzerindeki güçlü yayılma etkisi, sektörel kaynak bağımlılığı açısından anlaşılabilir bir durumdur. Ancak, oynaklık yayılımında en güçlü etkinin BIST 100 endeks getirisindeki değişikliklerden kaynaklanması ve bu ilişkinin nedensellik açısından da doğrulanması, borsa gösterge endeksi getirisinin BIST elektrik endeksindeki şirketler üzerinde önemli bir risk unsuru olduğu şeklinde yorumlanmaktadır. Dünya doğal gaz fiyatlarındaki değişikliklerin elektrik endeksi getirisinde gerek nedensellik gerekse oynaklık yayılımı açısından bir etki tespit edilmemesi, böyle bir etkinin olmadığı anlamına gelmeyebilir. Gelecek çalışmalar için doğal gaz fiyatlarındaki değişikliklerin etkisinin firma düzeyinde araştırılması önerilmektedir. 


\section{KAYNAKÇA}

ABDİOĞLU, Z. \& DEĞİRMENCİ, N. (2014). "Petrol Fiyatları-Hisse Senedi Fiyatları İlişkisi: BIST Sektörel Analiz", Kafkas Üniversitesi İktisadi ve İdari Bilimler Fakültesi Dergisi, 5(8), 01-24.

ACARAVCI, A., ÖZTURK, İ. \& KANDIR, S. Y. (2012). "Natural Gas Prices and Stock Prices: Evidence from EU-15 Countries", Economic Modelling, 29(5), 1646-1654.

AROURIA, M. E., JOUINI, J. \& NGUYEN, D. K. (2011). "Volatility Spillovers between Oil Prices and Stock Sector Returns: Implications for Portfolio Management", Journal of International Money and Finance, 30(7), 1387-1405.

AROURI, M. E., JOUINI, J. \& NGUYEN, D. K. (2012). "On the Impacts of Oil Price Fluctuations on European Equity Markets: Volatility Spillover and Hedging Effectiveness", Energy Economics, 34(2), 611-617.

BAE, K.H. \& KAROLYI, G. (1994). "Good News, Bad News and International Spillovers of Stock Return Volatility Between Japan and the U.S. Pacific-Basin", Finance Journal, 2(4), 405-438.

BÜBERKÖKÜ, Ö. (2021). "Risk-Getiri İlișkisinin Analizi: Türkiye Örneği", Finans Ekonomi ve Sosyal Araştırmalar Dergisi, 6(1), 14-25.

BP, British Petroluem, "BP Statistical Review of World Energy 2019", https://www.bp.com/content/dam/bp/business-sites/en/global/corporate/pdfs/energyeconomics/statistical-review/bp-stats-review-2019-full-report.pdf, 30.05.2020

CHEN, N.F., ROLL, R. \& ROSS, S. A. (1986). "Economic Forces and the Stock Market", The Journel of Business, 59(3), 383-403.

CHEUNG, Y. \& NG, L. (1996). "A Causality-in-Variance Test and Its Application to Financial Market Prices", Econometrics, 72(1996), 33-48.

DE SANTIS, G. \& GERARD, B. (1997). "International Asset Pricing and Portfolio Diversification with Time-Varying Risk", The Journal of Finance, 52(5), 1881-1912.

DEMIRALAY, S. \& GENCER, H. (2014). "Volatility Transmissions between Oil Prices and Emerging Market Sectors: Implications for Portfolio Management and Hedging Strategies", International Journal of Energy Economics and Policy, 4(3), 442-447.

DEKTMK, Dünya Enerji Konseyi Türk Milli Komitesi, "Dünya Enerji Görünümü 2018", https://www.dunyaenerji.org.tr/dunya-enerji-gorunumu-2018-yonetici-ozetiuea/,30.05.2020

ERYİĞİT, M. (2009). "Effects of Oil Price Changes on the Sector Indices of Istanbul Stock Exchange", International Research Journal of Finance and Economics, 1(25), 209-216.

ETKB, Enerji ve Tabii Kaynaklar Bakanlığı, "Denge Tabloları", https://www.eigm.gov.tr/trTR/Denge-Tablolari/Denge-Tablolari,01.06.2020

EWING, B. \& MALIK, F. (2016). "Volatility Spillovers Between Oil Prices and the Stock Market Under Structural Breaks", Global Finance Journal, 29, 12-23. 
GREEN, R., LARSSON, K., LUNINA, V. \& NILSSON, B. (2018). "Cross-Commodity News Transmission and Volatility Spillovers in the German Energy Markets", Journal of Banking \& Finance, 95, 231-243.

GÜLER, S., TUNÇ, R. \& ORÇUN, Ç. (2010). "Petrol Fiyat Riski ve Hisse Senedi Fiyatları Arasındaki İlişkinin Belirlenmesi: Türkiye'de Enerji Sektörü Üzerinde Bir Uygulama", Atatürk Üniversitesi İktisadi ve İdari Bilimler Dergisi, 24(4), 297-315.

GÜRLEVİK, F. \& GAZEL, S. (2020). "Enerji Fiyatlarındaki Değişimin Hisse Senedi Fiyatlarına Etkisi: BIST Elektrik Endeksi Üzerine Bir Uygulama", Ekev Akademi Dergisi, 82, 119-138.

IEA, International Energy Agency, "Data and Statistics", https://www.iea.org/data-andstatistics?country=WORLD\&fuel=Energy\%20supply\&indicator=TPESbySource, 01.01.2020.

IIASA, Uluslararası Uygulamalı Sistem Analizi Enstitüsü, "Fossil Energy", https://iiasa.ac.at/web/home/research/Flagship-Projects/Global-Energy-

Assessment/GEA_Chapter12_fossils_lowres.pdf, 01.06.2020.

İLARSLAN, K. (2021) "Uluslararası Fosil Yakıt Fiyatlarının Finansal Piyasalar Üzerindeki Etkisinin ARDL Sınır Testi ile İncelenmesi: 1986-2019 Dönemi Türkiye Örneği", Finansal Araştırmalar ve Çalışmalar Dergisi, 13(24), 143-158.

KAPUSUZOGLU, A. (2018). "Relationships Between Oil Price and Stock Market: An Empirical Analysis from Istanbul Stock Exchange (ISE)", International Journal of Economics and Finance, 10(8)

LIU, T., HE, X., NAKAJIMA, T. \& HAMORI, S. (2020). "Influence of Fluctuations in Fossil Fuel Commodities on Electricity Markets: Evidence from Spot and Futures Markets in Europe", Energies, 13(8), 1900

MJELDE, J. W. \& BESSLER, D. (2009). "Market Integration among Electricity Markets and Their Major Fuel Source Markets", Energy Economics, 31(3), 482-491.

MOHAMMADI, H. (2009). "Electricity Prices and Fuel Costs: Long-run Relations and Shortrun Dynamics", Energy Economics, 31(3), 503-509.

MOUTINHO, V., VIEIRA, J. \& MOREIRA, A. C. (2011). "The Crucial Relationship Among Energy Commodity Prices:Evidence From The Spanish Electricity Market", Energy Policy, 39(2011), 5898-5908.

MUÑOZ, M. P. \& DICKEY, D. (2009). "Are Electricity Prices Affected by the US Dollar to Euro Exchange Rate? The Spanish Case", Energy Economics, 31(6), 857-866.

NAKAJIMA, T. \& HAMORI, S. (2012). "Causality-in-Mean and Causality-in-Variance among Electricity Prices, Crude Oil Prices, and Yen-US Dollar Exchange Rates in Japan", Research in International Business and Finance, 26(3), 371-386.

NANDHA, L. \& FAFF, R. (2008). "Does Oil Move Equity Prices? A Global View", Energy Economics, 30(3), 986-997. 
NARAYAN, P. K. \& NARAYAN, S. (2010). "Modelling The Impact of Oil Prices on Vietnam's Stock Prices", Applied Energy, 87(1), 356-361.

NG, A. (2000). "Volatility Spillover Effects from Japan and the US to the Pacific-Basin", Journal of International Money and Finance, 19(2), 207-233.

OBERNDORFER, U. (2009). "Energy Prices, Volatility, and The Stock Market: Evidence From The Eurozone", Energy Policy, 37 (2009), 5787-5795.

ORDU, B. M. \& SOYTAŞ, U. (2015). "The Relationship Between Energy Commodity Prices and Electricity and Market Index Performances: Evidence from an Emerging Market", Emerging Markets Finance and Trade, 52(9), 1-16.

ORDU, B. M. \& SOYTAŞ, U. (2016). "The Relationship Between Energy Commodity Prices and Electricity and Market Index Performances: Evidence from an Emerging Market", Emerging Markets Finance \& Trade, 52, 2149-2164.

PARK, J. \& RATTI, R. (2008). "Oil Price Shocks and Stock Markets in The U.S. and 13 European Countries", Energy Economics, 30(5), 2587-2608.

SADORSKY, P. (2014). "Modeling Volatility and Correlations Between Emerging Market Stockprices and The Prices Of Copper, Oil And Wheat", Energy Economics, 43(2014), $72-81$.

SCHERNIKAU, L. (2016). The International Coal Trade (Second Edition): Why Coal Continues to Power The World, Cham, Switzerland: Springer.

SOYTAŞ, U. \& ORAN, A. (2008). "Dünya Petrol Fiyatlarındaki Değişim İMKB Elektrik Endeksine Nasıl Yansıyor?", 12. Ulusal Finans Sempozyumu, 216-222.

SOYTAŞ, U. \& ORAN, A. (2011). "Volatility Spillover from World Oil Spot Markets to Aggregate and Electricity Stock Index Returns in Turkey", Applied Energy, 88(1), 354360 .

TEİAŞ. Türkiye Elektrik İletim A.Ş., "2020 Y1lı Aylık Elektrik Üretim-Tüketim Raporları", https://www.teias.gov.tr/tr-TR/aylik-elektrik-uretim-tuketim-raporlari, 01.06.2020.

VARDAR, G., KURT-GÜMÜŞ, G. \& DELİCE, M. E. (2018). "The Impact of Oil Price Shocks on Sector Indices: Evidence from Borsa İstanbul", Business and Economics Research Journal, 9(2), 271-289.

YILANCI, V. (2009). "Yapısal Kırılmalar Altında Türkiye İçin İşsizlik Histerisinin Sınanması", Doğuş Üniversitesi Dergisi, 10(2), 324-335.

ZIVOT, E. \& ANDREWS, D. W. K. (1992). "Further Evidence on the Great Crash, the Oil Price Shock, and the Unit-Root Hypothesis", Journal of Business \& Economic Statistics, 10(3): 251-270. 
EKLER

Ek 1. ELEN ve DELEN Modelleri için Gecikme Uzunluğunun Belirlenmesi

\begin{tabular}{|c|c|c|c|c|c|}
\hline \multicolumn{7}{|c|}{ ELEN için Uygun Gecikme Uzunluğu } \\
\hline Gecikme & LR & FPE & AIC & SC & HQ \\
\hline 0 & NA & $6.32 \mathrm{e}-19$ & -24.87768 & -24.86383 & -24.87266 \\
\hline 1 & 2066.201 & $2.86 \mathrm{e}-19$ & -25.66943 & $-25.57242^{*}$ & $-25.63423^{*}$ \\
\hline 2 & 138.8394 & $2.79 \mathrm{e}-19$ & -25.69617 & -25.51601 & -25.63080 \\
\hline 3 & 104.7369 & $2.75 \mathrm{e}-19$ & -25.70945 & -25.44614 & -25.61390 \\
\hline 4 & 118.3765 & $2.70 \mathrm{e}-19$ & -25.72828 & -25.38181 & -25.60256 \\
\hline 5 & 86.33121 & $2.68 \mathrm{e}-19$ & -25.73437 & -25.30476 & -25.57849 \\
\hline 6 & 40.53938 & $2.72 \mathrm{e}-19$ & -25.72216 & -25.20940 & -25.53610 \\
\hline 7 & 62.09155 & $2.73 \mathrm{e}-19$ & -25.71866 & -25.12275 & -25.50243 \\
\hline 8 & 101.2489 & $2.69 \mathrm{e}-19$ & -25.73103 & -25.05197 & -25.48463 \\
\hline 9 & 66.76768 & $2.70 \mathrm{e}-19$ & -25.72955 & -24.96734 & -25.45298 \\
\hline $\mathbf{1 0}$ & $\mathbf{1 0 7 . 5 9 1 3}$ & $\mathbf{2 . 6 6 e - 1 9}$ & $-25.74469^{*}$ & -24.89933 & -25.43795 \\
\hline 11 & $55.32214^{*}$ & $2.67 \mathrm{e}-19$ & -25.73869 & -24.81017 & -25.40177 \\
\hline \multicolumn{7}{|c|}{ DELEN için Uygun Gecikme Uzunluğu} & \\
\hline Gecikme & LR & FPE & AIC & SC & HQ \\
\hline 0 & NA & $1.01 \mathrm{e}-20$ & -29.01320 & -28.99933 & -29.00816 \\
\hline 1 & 331.2083 & $9.12 \mathrm{e}-21$ & -29.11626 & $-29.01918^{*}$ & -29.08103 \\
\hline 2 & 152.6930 & $8.83 \mathrm{e}-21$ & -29.14854 & -28.96826 & $-29.08312^{*}$ \\
\hline 3 & 145.7324 & $8.57 \mathrm{e}-21$ & -29.17819 & -28.91471 & -29.08258 \\
\hline 4 & 112.4305 & $8.43 \mathrm{e}-21$ & -29.19466 & -28.84797 & -29.06885 \\
\hline 5 & 97.94988 & $8.34 \mathrm{e}-21$ & -29.20542 & -28.77553 & -29.04942 \\
\hline 6 & 69.66405 & $8.35 \mathrm{e}-21$ & -29.20490 & -28.69181 & -29.01872 \\
\hline 7 & 61.58520 & $8.38 \mathrm{e}-21$ & -29.20120 & -28.60490 & -28.98482 \\
\hline $\boldsymbol{8}$ & $\mathbf{1 1 3 . 6 2 9 9}$ & $\mathbf{8 . 2 4 e - 2 1 *}$ & $-29.21859^{*}$ & -28.53908 & -28.97201 \\
\hline 9 & 65.09294 & $8.25 \mathrm{e}-21$ & -29.21642 & -28.45371 & -28.93966 \\
\hline 10 & 64.11684 & $8.27 \mathrm{e}-21$ & -29.21393 & -28.36801 & -28.90697 \\
\hline 11 & 51.34109 & $8.34 \mathrm{e}-21$ & -29.20630 & -28.27718 & -28.86915 \\
\hline 12 & $68.11688^{*}$ & $8.34 \mathrm{e}-21$ & -29.20556 & -28.19324 & -28.83822 \\
\hline
\end{tabular}

